\title{
sciendo
}

\section{The SELF File and Immunity to Error Through Misidentification}

\author{
Manuel García-Carpintero \\ University of Barcelona
}

There are two diverging views on singular thoughts: a 'latitudinarian' or 'liberal' one (Sosa 1970, Hawthorne \& Manley 2012) appealing to Fregeans, on which thinking a de dicto proposition that predicates some property $f$ with respect to some individuating concept $a$ of $x$ suffices for having a singular thought about $x$; and a narrower one attractive to Millians, on which it requires acquaintance — some special relation binding the thinker with the object of reference, a causal psychological relation like perception or memory. In Mental Files, François Recanati advances a liberalization of the acquaintance view which, even if I do not find it fully convincing, I will not question here; I will assume that it deals well with Millian concerns from a perspective hospitable to the Fregean. ${ }^{1}$

Now, in the 1960s and 1970s Castañeda, Perry and Lewis argued that thoughts about oneself 'as oneself' — de se thoughts — raise special issues. In the first section I briefly survey the data, and Perry's and Lewis's contrasting proposals: while Lewis aims to account for de se thoughts by taking the subject away from such contents, which are thus properties instead of complete traditional proposi-

\footnotetext{
${ }^{1}$ Recanati allows that one may have a singular thought when one opens a file merely on the basis of descriptive information. Thus, Leverrier had singular thoughts about Neptune when he introduced the name, as I (2008) have argued is correct. However, against what I (2010) think, Recanati does not allow for singular thoughts in cases of merely imagined acquaintance, or in cases in which the acquaintance is expected but never materializes, because there is no object or because the subject never comes to be in the relation with it: 'The acquaintance relation may be anticipated without undermining the reference relation which is based on it, but if the acquaintance relation never comes about, the reference relation does not either' (2012a: 164).
}

Disputatio, Vol. V, No. 36, October 2013 
tions, Perry offers an account compatible with traditional views. I also discuss Stalnaker's argument for a form of the latter view, and Recanati's take on it in Mental Files. In the second section I take up Recanati's $(2007,2009)$ arguments for a subjectless view of the content of 'implicit' de se thought, on the basis that we can thus better explain the phenomenon of immunity to error through misidentification. I argue that this is not the case, and I suggest that such a view is in tension with Recanati's mental files approach to de re thought in general and the SELF concept in particular. I will thus take advantage of the occasion of this symposium on Mental Files to air a perplexity I have been harboring with regard to the compatibility of Recanati's Lewisian account of de se contents and the mental files approach to content-ingredients he has been developing in his work, which are fully articulated in Mental Files.

\section{De se thoughts}

Following Castañeda 1966, Perry 1979 and Lewis 1979 showed that thoughts about oneself 'as oneself' — de se thoughts — require special treatment, and advanced rival accounts. Perry introduces the problem with a celebrated example:

'I once followed a trail of sugar on a supermarket floor, pushing my cart down the aisle on one side of a tall counter and back the aisle on the other, seeking the shopper with the torn sack to tell him he was making a mess. With each trip around the counter, the trail became thicker. But I seemed unable to catch up. Finally it dawned on me. I was the shopper I was trying to catch.' (Perry 1979: 33)

Before his epiphany, Perry has, according to latitudinarian accounts of de re thought, a belief about himself (under the individuating concept the shopper with the torn sack) to the effect that he was making a mess; but this is insufficient for him to have the reflexive, selfconscious belief that he would express in accepting 'I am making a mess', the one that leads him to rearrange the torn sack in the cart.

As Perry points out, it will not help to opt for a narrower account of de re thought:

'Suppose there were mirrors at either end of the counter so that as I pushed my cart down the aisle in pursuit I saw myself in the mirror. I take what I see to be the reflection of the messy shopper going up the aisle on the other side, not realizing that what I am really seeing is a 
reflection of a reflection of myself.' (Perry 1979: 42)

Given that he is perceiving himself in the mirror, the narrower conception allows for Perry to have a de re belief about himself, to the effect that he is making a mess; but this still falls short of the reflective, self-conscious belief manifested by acceptance of 'I am making a mess' and the cleaning up behavior. Castañeda's amnesiac cases suggest that rich descriptive concepts are also unnecessary; for they are able to think about themselves in a fully self-conscious reflexive way, by using and understanding 'I' and related expressions for firstpersonal reference while knowing precious little about themselves.

Propositional attitudes and speech acts are individuated by representational contents that are taken to be propositions with absolute truth-values: given a full specification of a possible way for the world to be, propositions thus understood get a definite truth value with respect to it. Alternatively, propositions can be simply identified as classes of possible worlds, those with respect to which they are true. Thus, in believing that snow is white one represents worlds in which snow is white, and places the actual world among them. Lewis and Perry take de se thoughts to question this picture.

Lewis proposes to abandon the traditional theory of contents, and to take them to be properties instead of propositions: entities which are true or false, given a full characterization of a way for the world to be, only relative in addition to a subject and a time. Alternatively, the contents of propositional attitudes are, or at least select, not just classes or worlds, but rather classes of centered worlds: worlds together with a designated subject and a time. In coming to believe what he would express by accepting 'I am making a mess', Perry locates himself among all subjects making a mess at a given time and world.

On the traditional conception of contents the actual world is not part of the believed content, but in believing a proposition one ascribes it to the actual world at which the believing occurs; it is the attitude of believing, or the act of judging, which, as it were, as part of its 'illocutionary' nature, brings the world at which it occurs as the relevant one to evaluate the truth of the belief. A mere imagining with the same content would not similarly bring the actual world to bear, because imaginings are not evaluated as true or otherwise relative to whether the actual world where the imagining occurs is 
correctly represented by their contents. Similarly and by analogy, on Lewis's view it is the attitude of believing itself, as opposed to its content, which brings to bear the subject and time relevant for the evaluation of its truth or falsity. Subjects who come to believe what they would express in English by uttering 'I am making a mess' believe the same contents, in the way that subjects who believe that snow is white at different worlds believe the same contents. This provides a nice solution to the initial problem of de se thought: if no descriptive conception of the subject (including ones allowing for de $r e$ thought on the narrow conception $\mathrm{N}$ ) is sufficient for de se thought, and none appears to be needed, this is on Lewis's view because the subject is not represented as part of the content, but is brought to bear for purposes of evaluation by the act of judging itself, not by its content. These perspectival contents that Lewis's account posits have made a strong comeback to the philosophical scene in recent years, in the so-called relativist accounts advanced by writers such as Kölbel 2004, Egan 2007, 2010 or McFarlane 2003 for different areas of discourse: judgments of taste, epistemic modals, future-tense claims on the assumption of indeterminism, among others.

On Perry's alternative view, we should distinguish the content or object of the belief from the belief state through which it is accessed. The content is just a traditional proposition, de dicto or de re. The state is a specific condition of the subject, by being in which a given content is believed. Contents help to account for the role that propositional attitudes constitutively have in appraising the rationality of the subject, the adequacy of his beliefs to his evidence and of his actions to his beliefs and desires, the desirability of his desires, etc. But only in a coarse-grained way: for a full account of rational action we need not just the content, but also the specific state through which the content is accessed. In line with Frege's puzzles, the previous cases involving de se thoughts show that traditional contents are not enough to appraise rationality and cognitive significance; ways of accessing them should also be taken into consideration.

Belief states themselves must hence have some kind of meaning or significance, if they are to have a role in appraising the rationality of actions or inferences. In his original account, Perry 1979 appeals to Kaplan's 1989 distinction between character and content to characterize the significance of states. Utterances of 'he is making a mess' and 
'I am making a mess' might have, in their contexts, the same singular content, but they have different characters. Similarly, Perry's belief state when he looks at what is in fact his own reflection in the mirror, and later when he catches up, are different states with the same content; given the differences in rational action to be expected from one and the other, states themselves must have a role in the explanation of action and the cognitive significance of the belief in virtue of their character-like meaning.

Now, Stalnaker (1981: 145-8) objected to accounts such as Lewis's and the original one by Perry just presented on the grounds that they cannot capture an 'informational content' that is an essential feature of utterances including essential indexicals, and advanced an alternative account appealing to the 'diagonal propositions' that he (1978) had introduced earlier. Like Perry, I prefer to think in terms of structured propositions, as opposed to possible-world ones (and in fact take them to be ontologically more fundamental), so I will not present the Perry-Stalnaker debate in terms of diagonal propositions; I will present it instead in terms of what I take to be essentially equivalent token-reflexive structured propositions. ${ }^{2}$

Let us imagine a variation on Perry's supermarket story in which, contemplating the situation and realizing what is going on, a kind shopper warns Perry, which leads to Perry's epiphany. He thereby comes to accept 'I am making a mess' after being told 'you are making a mess'. On Perry's original view the contents of the beliefs thereby expressed are the ordinary, coarse-grained de re propositions which are conveniently identical for the two utterances. However, as we know, this singular content does not account for what Perry comes to know after the epiphany: he already believed it beforehand. Nevertheless, it seems that whatever explains Perry's distinctive behavior after the epiphany was in this variation of the story communicated to him by the other shopper's utterance.

How could Perry's or Lewis's proposals account for this? The character-like contents corresponding to the shopper's utterance, 'you are making a mess', are very different from those corresponding to the ones by means of which Perry would express his acquired knowledge, 'I am making a mess'. The properties that the shopper

${ }^{2}$ The reader might find further elaboration in my 2006a. 
and Perry rationally self-attribute differ (addressing someone who is making a mess, making a mess, respectively), and the corresponding perspectival contents are similarly different. Alternatively put, it would be absurd for Perry to ascribe to himself the property that the samaritan shopper expresses — to wit, that of being addressing someone who is making a mess. For Lewis and Perry to deal with this consistently with their accounts, they should elaborate them so as to explain how it is that, in virtue of the shopper expressing a certain de se content, Perry comes to learn a different one.

On the simplest account of successful communication, the episode should be explained by Perry's learning the very same content that the samaritan shopper expressed. This is what Stalnaker's account in terms of diagonal propositions or token-reflexive contents purports to offer. We can think of the meaning of indexicals like 'I' or 'you' as token-reflexive rules, which, given a particular token, fix its referent relative to some contextual property: being the speaker who produced it, or its (most salient) addressee. This provides a descriptive (but not purely general) conception of the referent; in the case of the samaritan utterance of 'you are making a mess', we have a token-reflexive conception associated with the particular case of 'you', the addressee of that token. ${ }^{3}$ Both the samaritan shopper and Perry can share this way of representing him. So we have here an ordinary content, determining a traditional proposition, which is communicated from one to the other: the one we could explicitly articulate with 'the addressee of that token of 'you' is making a mess'.

Perry 1993 accepts that, for the kind of consideration about informational content that Stalnaker pointed out, these token-reflexive contents provide a better representation of the significance of beliefstates than the one he had earlier suggested in terms of Kaplanian characters. As Perry 2006 explains, however, this refined version of his account can be taken in the proper way if it is to provide an at least prima facie successful account for de se thoughts. On this interpretation, the proposal is just a refined way of understanding the significance of belief-states; but an adequate account of de se contents (hence of the nature of attitudes and speech acts in general) still re-

${ }^{3}$ I have discussed the role of these contents in detail elsewhere (1998, 2000, 2006a). 
quires the distinction between belief-contents and belief-states (ways of accessing the content). The modification of Perry's original proposal lies only in that now the significance of belief-states is characterized in the traditional propositional way that token-reflexive contents afford.

This still leaves us with the task of explaining the nature of states and contents and their interrelation. Perry has an account on which states are mental particulars that may be classified by their 'official contents' (the coarse-grained singular propositions) and also by a plurality of other finer-grained propositional contents, useful for different explanatory purposes. In my view, the appeal to the state/content distinction in the case of de se thoughts is just a particular case of the proper way to understand a Fregean view on the attitudes, which I $(2000,2006$ a) have argued requires ascribing a presuppositional nature to reference-fixing senses. I cannot elaborate on the details of my own view of de se senses here. ${ }^{4}$

Recanati (2012a: 211-18) provides an interesting account of the communication of de se contents that is compatible with this. On his proposal, the concepts/mental files that the speaker (the samaritan shopper in the variation on Perry's original story above) expresses and the hearer (Perry) comes to entertain as a result differ, as it should be, for Perry's is his own Self concept, while this is not the one in the thought that his informant gives voice to. However, the latter evokes the former, because they share something: the linguistic sense of the token indexical that the speaker uses, the addressee of this very token of 'you'. I will come back to this below when I consider the consistency of Recanati's perspectival content account of de se thoughts with his views on the SELF file.

\footnotetext{
${ }^{4}$ Peacocke (1983: Chapter 5; 2008: Chapter 3; 2012), Higginbotham 2003 and Howell 2006 defend different proposals I am sympathetic to. On all of them, as Peacocke (2012: 145) puts it, it is constitutive of the SELF concept as it occurs in a de se attitude-state that it refers to the thinker of the attitude. A simple version of this suggestion assumes a language of thought; the difference between the state individuated by a sentence corresponding to 'I am making a mess' and another individuated by 'the addressee of that token is making a mess' is that only the former includes an expression whose reference rule aims to pick out its subject.
} 


\section{De se thoughts and immunity to error through misiden- tification}

Recanati 2007 argues for a (moderate) relativist account of some contents; in particular, he argues for a perspectival content account of 'basic' or 'implicit' de se thoughts, on which their possible-worldcontents must be given by centered worlds, along the lines of Lewis's. Recanati offers a new argument for this sort of account; he defends it on the basis of observations about the phenomenon that Shoemaker characterized as immunity to error through misidentification ('IEM' henceforth): $:^{5}$

'to say that a statement ' $a$ is $\mathrm{j}$ ' is subject to error through misidentification relative to the term ' $a$ ' means that the following is possible: the speaker knows some particular thing to be $\mathrm{j}$, but makes the mistake of asserting ' $a$ is j' because, and only because, he mistakenly thinks that the thing he knows to be $\mathrm{j}$ is what a refers to.' (Shoemaker 1968: 557) ${ }^{6}$

I will argue that IEM does not support the perspectivalist view, and suggest that rather the opposite is true. In more recent work, Recanati (2009 and 2012b) acknowledges some of the points that I will make, but he still defends the perspectivalist proposal on the basis of considerations about IEM. I will argue that they are unconvincing. ${ }^{7}$ Moreover, I will argue that the Mental Files take on the SELF concept and proto-concept is in tension with the account.

Consider the moment in Perry's story when he sees what in fact is his image in a mirror with a torn sack. Imagine another variation on the story, in which this is in fact the ground for Perry's epiphany, because this time he recognizes himself in the mirror; suppose then that he judges on this basis what he would express by 'I am making

${ }^{5}$ Shoemaker suggests that IEM captures some of Wittgenstein's points about uses of 'I' 'as subject' vs. uses of 'I' 'as object' in the Blue Book.

${ }^{6}$ Pryor 1999 offers an alternative propositional characterization, free from concerns that this linguistic characterization — useful as a starting point — might raise. Pryor's characterization also highlights the relativity to ways of reaching the relevant judgment and to normal circumstances that, as the examples below will make clear, any proper characterization should contemplate: a judgment can be IEM if made on a given epistemic basis in normal circumstances, and not if made on different bases or under abnormal conditions.

${ }^{7}$ Stanley (2011: 91-3) and Morgan 2012 make related objections to Recanati. 
a mess'. Made on such epistemic grounds, the claim is exposed to the error that Shoemaker identifies: Perry might have been wrong in identifying himself with the person whose back is reflected in the mirror; he would then be right that someone is pushing a cart with a torn sack and is thus making a mess, but wrong to think that it is he who is making a mess. In the original version of the story, the epiphany comes instead from Perry seeing that he is pushing a cart with a torn sack. Consider Perry's physical self-ascription, 'I am pushing a cart with a torn sack', made on the basis of his visual perception of the scene around him; or his psychological self-ascription, 'I see that I am pushing a cart with a torn sack'. Neither of these claims appears to be open to that sort of error; nor is the thought he expresses by 'I am making a mess', when based on such epistemic grounds.

These examples show that, if there is a connection between de se thoughts and IEM, it must be indirect; for the thoughts Perry expresses by accepting 'I am making a mess' in both cases are de se. The subtler connection might be this: 'I'-thoughts that are IEM are fundamentally de se; those that are not are only de se derivatively, in that, in making them by using the first-person concept, the speaker identifies himself as the object of other, fundamentally de se thoughts. Recanati's claims based on IEM on behalf of the property account of de se thought concern only the fundamentally de se. He (2007, 177) thus distinguishes explicit from implicit de se thoughts. The former are attitudes to traditional, full-fledged propositions, the latter to truncated perspectival propositions.

Various writers including John Campbell, Christopher Peacocke and Crispin Wright have developed an account of IEM suggested by Evans that Wright 2012 calls 'the Simple Account'. On the Simple Account, non-IEM thoughts are (roughly) thoughts the structure of whose epistemic justification depends on an identity claim; ${ }^{8}$ thus, for instance, Perry's judgment 'I am making a mess' in the first version of the story in the second paragraph of this section, which was not IEM, depends on Perry's identity judgment, I am that person reflected

\footnotetext{
${ }^{8}$ I say 'roughly' because there are further cases that are also not IEM but whose justification exhibit a more complex inferential structure, including the cases that Pryor 1999 calls 'which-misidentification; cf. also Recanati 2012 and Wright 2012.
} 
in the mirror. This is why he might coherently consider that, although the existential 'part' of his claim — that someone is making a mess - is correct, he is mistaken in the identification, and it is not in fact he himself but someone else who is making a mess. On the Simple Account, IEM thoughts are negatively characterized as those that are not thus dependent on an identity claim.

This account crucially relies on the notion of doxastic justification, hence on the problematic basing relation. There are well-known discrepancies among contemporary epistemologists that have immediate resonance for our present issue. Certainly, that a judgment A is epistemically based on a certain claim B cannot require that the subject phenomenologically experiences his coming to judge A as a result of an inference in part from B; for Perry might well lack such inferential phenomenology in the above example of non-IEM thought. Consider Moore's (in-)famous inference, (i) here are two hands, (ii) if there are hands, there is an external world, hence (iii) there is an external world. Given its validity, someone who judges (i) is thus rationally committed to (iii); but there are different ways of understanding such commitments. Pryor 2004 distinguishes two epistemological attitudes we may have with respect to them, a liberal and a conservative one. On the conservative attitude, having prima facie justification to believe (i) requires antecedent justification to believe (iii); the liberal denies this, even though he agrees that evidence against (iii) would defeat our justification to believe (i). I would further distinguish two versions of the conservative attitude; on the most straightforward conservative-conservative version, justification for (i) would require a priori or empirical evidence for (iii); on a liberal-conservative one along lines explored by Wright (2004), it is enough if (iii) is a presupposition that one is entitled to make by default.

These views carry over to the status of identity claims that one might discern in the justificatory structure of our singular thoughts. The conservative-conservative attitude is the proper one concerning Perry's identification with the person whose back he sees in the mirror. Consider, however, the judgments mentioned earlier as examples of IEM: Perry's physical self-ascription that he is pushing a cart with a torn sack, made on the basis of visual perception, or his psychological self-ascription that he sees that he is pushing a cart 
with a torn sack. Shoemaker would consider them as cases of circumstantial, not absolute IEM; they are de facto IEM but under weird circumstances they could be subject to error through misidentification. Imagine, for instance, that the science fiction technologies that films like Avatar contemplate could allow to block our own visual impressions and receive instead those coming from another body. ${ }^{9}$ Under those circumstances, Perry's judgments might be wrong because of the mistaken identification of himself with the body that is the source of the relevant visual impressions. We can interpret this in terms of the distinction between the liberal-conservative and the conservative-conservative attitudes. Even if the subject reasonably and in fact correctly took for granted in the context the identity premise, so that the judgment did not depend on it, there are contexts in which epistemically the judgment must be taken as made on the basis of the identity premise, for a circumstance in which it fails is a relevant alternative.

On this proposal, the commitment to identifications that ordinary self-ascriptions based on visual perception in fact carry are understood along the lines of the liberal-conservative proposal above, as opposed to the conservative-conservative view that suggests itself as more appropriate for the mirror example: these identities are in normal contexts presuppositions to which we are entitled by default, without the need to have ordinary a priori or empirical evidence for them. ${ }^{10}$ We do not need to go into these issues any further. Note just that the explanation that the Simple Account affords appeals to the absence of an identity claim in the justificational structure; Recanati's explanation appeals instead to the absence of a conception of the self in the content of the IEM judgments. The Simple Account helps us to distinguish two senses for a thought to have an identification component. In the first sense ('identification ${ }_{p}$ '), the epistemic grounds for the thought include an identity-premise. In the second sense ('identification ${ }_{\mathrm{C}}^{\text {') }}$, the thought includes a concept that identifies what it is about. On the Simple Account, having an identification $_{\mathrm{C}}$ component is compatible with a thought being IEM; for being

${ }^{9}$ Dennett 1978 imagines such a scenario.

${ }^{10}$ Cf. Coliva 2006, 2012 and Wright (2012: Sections 7-8); cf. also Peacocke (1983: 139-151) and Peacocke (2008: 92-103). 
IEM is lacking an identification ${ }_{\mathrm{P}}$ component, and thoughts having identification $_{\mathrm{C}}$ components may well be identification $_{\mathrm{P}}$ free - they might even be epistemically basic. In contrast, Recanati's account explains IEM by the absence of an identification ${ }_{\mathrm{C}}$ element.

The Simple Account opens the possibility of thoughts including identification ${ }_{C}$ components, which are nonetheless IEM with respect to them. And it seems to be the case that there are such thoughts. Wright 2012 offers as examples 'you are very close' and 'he is a long way off', both based on observation; Peacocke 2008, 'this keyboard is black', again based on observation. Hence, Recanati's 2007 account of IEM will not do. Recanati 2009, 2012b accepts this; he accepts it even for some first-personal IEM thoughts. Thus, a thought expressed by 'my legs are crossed', based on proprioceptive evidence, is IEM on his original account because the content is just the property of having crossed legs, which the subject self-ascribes. However, the thought expressed by 'it is my legs, not my neighbor's, that are crossed' cannot plausibly be considered as not including the concept of the thinker's leg. Nonetheless, it is still (circumstantially) IEM. Recanati suggests (2009: 259; 2012b: Sections 2.2 and 2.3) that this is only so because the 'subject-explicit' thought is derived through a process he calls 'reflection' from a 'subject-implicit' property-ascription, and thus has the same grounds as the latter, lacking an identity-premise:

'a judgment is immune to error through misidentification if it is implicitly de se, that is, if the subject is not represented in the content of the judgment but his or her involvement is secured by the mode of the grounding experience; yet an explicit de se thought may also be IEM if it has the same grounds as an implicit de se thought.'

But how could this work for demonstrative thoughts? Recanati (2012b: Section 3) justifies the extension of the proposal to that case, but Wright 2012 raises serious concerns.

It thus seems that the perspectival content account of first-personal thoughts is no better placed vis-à-vis IEM than the token-reflexive proposal outlined in the previous section. On the contrary, the failure of Recanati's attempt to extend his proposal to explain the IEM character of explicit (SELF concept involving) de se thoughts to IEM thoughts relative to demonstrative concepts in general suggests that the explanation of the IEM character of a thought (if there 
is one) must be compatible with its having a full traditional proposition as content. Such an explanation, I submit, should come from the broadly token-reflexive nature that the alternative to the perspectival content view presented in the previous section advances, i.e., of the relevant identification ${ }_{C}$. Here is the core of a suggestion. Deployment of individual concepts takes for granted reference-fixing information. A thought of the form $A$ is $P$ is IEM when the ascribed property $P$ is already ascribed to the referent of the concept $A$ as part of its background reference-fixing information. ${ }^{11}$ On this suggestion, when being $P$ is individuative, the identity $A$ is the $P$ is not a premise in the justificational structure of the judgment, but is rather (either de facto, i.e., merely circumstantially, or de jure) taken for granted in deploying concept $A$.

At first sight at least, to me a token-reflexive account of de se thoughts incorporating the kernel of an account of IEM just outlined fits Recanati's 2012a views on the SELF concept better than the perspectival content account. Simply put, mental files are individual concepts, and concepts are ingredients of contents. If the account of de se thoughts is that they deploy the Self mental file, then the contents of de se thoughts have this concept as an ingredient. Recanati's account of the communication of de se contents, outlined in the previous section, appears to assume the same. In the terminology used above, Recanati's account of de se thoughts and their communication appears to involve an identification ${ }_{\mathrm{C}}$ - the SELF file.

Now, this only applies, I guess, to Recanati's 'explicit' de se thoughts. He (2012a: 64) does envisage a SelF* 'proto-file', which, unlike the full SeLF file, 'can only host information gained 'from inside', in the first-person way and hence does not obey Evans's 'Generality Constraint'. I suppose the idea is that proto-files are vehicles for nonconceptual contents, and that it is the SELF* proto-file that figures in basic, 'implicit' de se contents. But this does not help. On the best account I know of the conceptual/non-conceptual distinction (cf. García-Carpintero 2006b, Heck 2007) the difference has to do with the nature of the content-vehicles, in particular with their inferential potential — which is consistent with Recanati's appeal to

${ }^{11}$ For the de se case, Peacocke (2012: 148-9) provides two suggestive examples that can be understood along these lines. 
breakdown of the Generality Constraint to characterize nonconceptual content. On this view, vehicles for nonconceptual contents still make contributions to contents; hence no justification for the perspectival content account of de se thoughts can be gleaned from this either. Contentful states involving the SELF* proto-file still appear to involve an identification ${ }_{\mathrm{C}} \cdot{ }^{12}$

I have taken advantage of the occasion of this symposium on Mental Files to question Recanati's (2007, 2009) grounds for his Lewisian account of de se contents, and also its compatibility with the mental files approach to content-ingredients articulated in the book. In the first section, I have contrasted the Lewisian, perspectival content approach with a token-reflexive elaboration on the Perry-Stalnaker traditional alternative. I presented the communication problem raised in favor of the latter, and I have suggested that Recanati's proposal to deal with it in the book appears to fit better the latter view. In this section I have argued that IEM does not give any advantage to the Lewisian view; rather, the opposite appears to be the case. ${ }^{13}$

Manuel García-Carpintero
Departament de Lògica, Història i Filosofia de la Ciència
Universitat de Barcelona
Montalegre, 6-8, $4^{\mathrm{a}}$ planta
08001 Barcelona
Spain
m.garciacarpintero@ub.edu

\section{References}

Castañeda, Hector. 1966. 'He': A Study in the Logic of Self-Consciousness. Ratio 8, 130-157. Reproduced in Castañeda 1999.

Castañeda, Hector. 1999. The Phenomeno-Logic of the I: Essays on Self-Consciousness,

${ }^{12}$ Cf. also Peacocke's (2012: 154-6) criticism of Perry's 2002 related view.

${ }^{13}$ Financial support for my work was provided by the DGI, Spanish Government, research project FFI2010-16049 and Consolider-Ingenio project CSD2009-00056; through the award ICREA Academia for excellence in research, 2008, funded by the Generalitat de Catalunya; and by the European Community's Seventh Framework Programme FP7/2007-2013 under grant agreement no. 238128. Thanks to Annalisa Coliva, Jose Díez, Ernest Sosa, and Stephan Torre for very helpful discussion and comments, and to Michael Maudsley for the grammatical revision. 
ed. by J. Hart and T. Kapitan, Bloomington: Indiana University Press.

Coliva, Annalisa. 2006. Error through Misidentification: Some Varieties. Journal of Philosophy 103: 403-425.

Coliva, Annalisa. 2012. Which 'Key to All Mythologies' about the Self? A Note on where the Illusions of Transcendence Come from and How to Resist Them. In Immunity to Error Through Misidentification: New Essays, ed. by Simon Prosser and François Recanati, 22-45. Cambridge University Press.

Dennett, Daniel. 1978. Where Am I? In Brainstorms. Cambridge, Mass.: MIT Press.

Egan, Andy. 2007. Epistemic Modals, Relativism and Assertion. Philosophical Studies 133: 1-22.

Egan, Andy. 2010. Disputing about Taste. In Disagreement, ed. by Richard Feldman and Ted Warfield, 247-286. Oxford: OUP.

Evans, Gareth. 1982. The Varieties of Reference. Oxford: Clarendon Press.

García-Carpintero, Manuel. 1998. Indexicals as Token-Reflexives. Mind 107: 529-563.

García-Carpintero, Manuel. 2000. A Presuppositional Account of ReferenceFixing. Journal of Philosophy XCVII (3): 109-147.

García-Carpintero, Manuel. 2006a. Two-dimensionalism: a Neo-Fregean Interpretation. In Two-Dimensional Semantics, ed. by Manuel García-Carpintero \& J. Macià, 181-204. Oxford: Oxford University Press.

García-Carpintero, Manuel. 2006b. Nonconceptual Modes of Presentation. European Review of Philosophy, 6: The Structure of Nonconceptual Content, ed. by C. Van Geen \& F. de Vignemont. Stanford: CSLI, 65-81.

García-Carpintero, Manuel. 2008. Singular Thought and the Contingent A Priori. Revue Internationale de Philosophie, special issue Philosophy of Mind edited by Joëlle Proust 62: 79-98.

García-Carpintero, Manuel. 2010. Fictional Singular Imaginings. In New Essays on Singular Thought, ed. by Robin Jeshion, 273-299. Oxford: Oxford University Press.

Hawthorne, John and Manley, David. 2012. The Reference Book, Oxford: Oxford University Press.

Heck, Richard G. Jnr. 2007. Are There Different Kinds of Content? In Contemporary Debates in Philosophy of Mind, ed. by Brian P. McLaughlin \& Jonathan Cohen, 117-138. Oxford: Blackwell.

Higginbotham, James. 2003. Remembering, Imagining, and the First Person. In Epistemology of Language, ed. by Alex Barber, 496-533. Oxford: Oxford University Press.

Howell, Robert. 2006. Self-Knowledge and Self-Reference. Philosophy and Phenomenological Research 72: 44-69.

Kaplan, David. 1989. Demonstratives. In Themes from Kaplan, ed. by Joseph Almog, John Perry and Howard Wettstein, 481-563. Oxford: Oxford University Press.

Kölbel, Max. 2004. Indexical Relativism vs Genuine Relativism. International Journal of Philosophical Studies 12: 297-313.

Lewis, David. 1979. Attitudes De Dicto and De Se. Philosophical Review 88: 513-43. Also in D. Lewis, Philosophical Papers vol. 1, Oxford: Oxford University Press.

MacFarlane, John. 2003. Future Contingents and Relative Truth. Philosophical Quarterly 53: 321-336.

Morgan, Daniel. 2012. Immunity to Error through Misidentification: What Does It Tell Us about the De Se. In Immunity to Error Through Misidentification: New Essays, ed. by Simon Prosser and François Recanati, 104-123. Cambridge University Press.

Peacocke, Christopher. 1983. Sense and Content. Experience, Thought, and their Rela- 
tions. Oxford: Clarendon Press.

Peacocke, Christopher. 2008. Truly Understood. Oxford: Oxford University Press. Peacocke, Christopher. 2012. Explaining De Se Phenomena. In Immunity to Error Through Misidentification: New Essays, ed. by Simon Prosser and François Recanati, 144-157. Cambridge University Press.

Perry, John. 1979. The Problem of the Essential Indexical. Noûs 13: 3-21. Also in his The Problem of the Essential Indexical and other Essays, Oxford: Oxford University Press, 1993, 33-50, from which I quote.

Perry, John. 1993. Postscript to The Problem of the Essential Indexical. In The Problem of the Essential Indexical and other Essays, 50-52. Oxford: Oxford University Press.

Perry, John. 2001. Reference and Reflexivity. Stanford: CSLI Publications.

Perry, John. 2002. The Self, Self-Knowledge and Self-Notions. In Identity, Personal Identity, and the Self, 189-213. Indianapolis: Hackett.

Perry, John. 2006. Stalnaker and Indexical Belief. In Content and Modality: Themes from the Philosophy of Robert Stalnaker, ed. by Judith Thomson and Alex Byrne, 204-221. Oxford: Clarendon Press.

Pryor, James. 1999. Immunity to Error Through Misidentification. Philosophical Topics 26: 271-304.

Pryor, James. 2004. What Is Wrong with Moore's Argument? Philosophical Issues 14: 349-378.

Recanati, François. 2007. Perspectival Thought, Oxford: Oxford University Press. Recanati, François. 2009. De re and De se. Dialectica 63: 249-269.

Recanati, François. 2010. Singular Thought: In Defense of Acquaintance. In New Essays on Singular Thought, ed. by Robin Jeshion, 141-189. Oxford: Oxford University Press.

Recanati, François. 2012a. Mental Files. Oxford: Oxford University Press.

Recanati, François. 2012b. Immunity to Error through Misidentification: What It Is and Where It Comes from. In Immunity to Error Through Misidentification: New Essays, ed. by Simon Prosser and François Recanati, 180-201. Cambridge University Press.

Shoemaker, Sidney. 1968. Self-Knowledge and Self-Awareness. Journal of Philosophy LXVC: 555-567.

Sosa, Ernest. 1970. Propositional Attitudes De Dicto and De Re. The Journal of Philosophy, Vol.67, No. 21: 883-896.

Stalnaker, Robert. 1981. Indexical Belief. Synthese 49: 129-151. Also in his Context and Content, Oxford: Oxford University Press, 1999, 130-149, to which I refer.

Stalnaker, Robert. 2008. Our Knowledge of the Internal World. Oxford: Oxford University Press.

Stanley, Jason. 2011. Know How. Oxford: Oxford University Press.

Wright, Crispin. 2004. Warrant for Nothing (and Foundations for Free)? Proceedings of the Aristotelian Society, Supplementary Volume 78: 167-212.

Wright, Crispin. 2012. Reflections on François Recanati's 'Immunity to Error through Misidentification: What It Is and Where It Comes from'. In Immunity to Error Through Misidentification: New Essays, ed. by Simon Prosser and François Recanati, 247-280. Cambridge University Press. 